\title{
Application of Intelligent Optimization of Solar Air Heating System in Large Buildings
}

\author{
Jiazheng Yu \\ Zhejiang University of Technology, Zhejiang Hangzhou, China
}

Keywords: natural ventilation; intelligent building; architectural design; regional architecture; energy conservation; solar energy

\begin{abstract}
With the increasing pressure of global climate and environmental change, strengthening building energy efficiency and developing green building to protect the earth's environment has become a hotspot. Among them, in the ventilation of buildings, it is now widely used to adjust the temperature and humidity by mechanical ventilation to meet the needs of the residents. The advantage of mechanical ventilation lies in its convenience and fast speed. It can achieve the temperature and humidity that people want in a short time, but the pollution and malpractice it brings are also obvious. Natural ventilation is an effective means of building energy saving, which plays an important role in reducing energy consumption and improving indoor comfort. The advantages of natural ventilation technology are introduced, whose principle is analyzed, and the realization method of natural ventilation technology is discussed.
\end{abstract}

\section{Introduction}

With the continuous development of air conditioning technology, people are more and more active in controlling indoor environment, creating unprecedented indoor climate requirements, so that people gradually fade the application of climate suitability technology of natural ventilation. However, in today's global energy crisis, energy-saving pressure increases, and the deterioration of air quality (IAO) building syndrome (SBS) occurred under the condition of natural ventilation, people have to re-examine the traditional climate suitability technology, the old and effective technology has been hitherto unknown attention in today's natural ventilation.

With the continuous development of air conditioning technology, people are more and more active in controlling indoor environment, creating unprecedented indoor climate requirements, so that people gradually fade the application of climate suitability technology of natural ventilation. However, in today's global energy crisis, energy-saving pressure increases, and the deterioration of air quality (IAO) building syndrome (SBS) occurred under the condition of natural ventilation, people have to re-examine the traditional climate suitability technology, the old and effective technology has been hitherto unknown attention in today's natural ventilation.

As the most energy saving and clean energy, solar energy heating is one of the effective ways to reduce energy and reduce the fog and haze. China is a large country of solar energy and photothermal industry. It is one of the richest areas of solar energy in the world. However, the utilization of solar energy is still focused on the production of domestic hot water, which has not yet been widely applied to heating.

Solar heat and light have many advantages, such as universality, huge e same time, solar collector has the disadvantages of large area, dispersibility, instability, high initial investment and low efficiency. Therefore, it is necessary to actively seek a kind of energy-saving and environmental protection technology, and the combined application of solar energy to achieve the purpose of heating. Heat pump technology is no doubt a good choice. Among them, the air source heat pump is more than other forms of heat pump, and does not require much of the hard environment conditions such as site, installation area geology and underground water volume. It becomes the best auxiliary heat source for solar thermal heating. 


\section{Joint operation mode of solar air source heat pump}

Solar energy and air source heat pump system is the most advanced and energy-saving central hot water heating mode at present. It can not only meet the needs of hot water, but also improve the temperature of the system for heating. The whole system consists of solar collector, air source heat pump, heat storage tank, heat exchange system, water pump and terminal system.

Due to the contemporary architectural design of urban construction is relatively dense, rarely consider the installation position of the solar collector, the roof area is very limited, effective space optimization design of solar collector solar and air source heat pump according to the actual use of the roof, the lack of heat using air source heat pump efficiency is very high are added, even in the most adverse weather conditions under the condition, also can meet the heating requirements of heating temperature. The maximum use of solar energy to reduce the energy required by electric auxiliary heating.

\subsection{Operation principle of 2.1 joint system}

During the winter heating, the heat is stored in the storage tank through a solar collector. When the heating water temperature is greater than the set temperature of the solar thermal, using solar energy, air source heat pump host does not start; when the temperature is higher than the solar thermal system and return water temperature below the water temperature for heating, the use of solar and air source heat pump engine combined heating; when the solar thermal heating temperature is lower than the water temperature, the air alone the source heat pump heating. In addition, the auxiliary heater can be set up in the heat storage tank to meet the needs of the bath water when the weather is not good in winter. In the case of refrigeration demand, the air source heat pump can also be used to refrigerate in the summer.

\subsection{Operation principle of 2.2 air source heat pump}

Air source heat pump (air source heat pump) is an energy-saving and environmental protection technology based on the principle of reverse Kano cycle. The air source heat pump system transfers energy from low temperature to high temperature by inputting a small amount of high grade energy (electric energy). In the outdoor air as the heat source, the refrigerant (R417a or CO2) for the media, refrigerant in the evaporator (or condenser) to absorb the energy in the air, and then compressed by the compressor heating (or cooling), the heat exchange device will heat (or cold) transfer water, through indoor heating buildings to the end (or cooling), also can be directly used for hot water supply. Normally air source heat pumps can absorb about $2 \mathrm{KW}$ of heat or cold from the air for each energy consumed by $1 \mathrm{KW}$. With the input $1 \mathrm{KW}$ power, the energy of the $3 \mathrm{KW}-3.5 \mathrm{KW}$ can actually be generated.

(electricity, fuel) and boiler heating system compared to fuel energy boiler heating can be more than $90 \%$ of the electrical energy into heat or $70-90 \%$, for the user, and the thermal efficiency of the air source heat pump can reach $350 \%$, so the air source heat pump to save $50 \%-70 \%$ than electric boiler heating power, the ratio of fuel boiler saving energy of $30 \%-40 \%$.

\subsection{Characteristics of solar energy and air source heat pump system}

The system provides the heat source with the combined operation of the solar energy set and the heat pump unit, which effectively reduces the cost of the single solar system heating. Make up for the instability of solar energy. According to the actual roof area, we should arrange the proportion of solar collector and air source heat pump reasonably, maximize the use of renewable solar energy, and meet the needs of households. The system is not burning, the water and electricity are separated, the water temperature is moderate and constant, without any danger. The system adopts regenerative system, and the system runs stably. It separates heating system from domestic hot water system, and uses two sets of heat storage water tanks. It can also satisfy heating and central hot water demand, and the system is relatively independent. The temperature is set separately, and it has no influence on each other. Not only to meet the winter heating, summer refrigeration, but also to meet the construction of hot water in the four seasons of the year. The real realization of a set of 
three equipment. In the operation of the system, the solar energy system will always serve as a priority start system, making full use of solar energy, and then start the air source heat pump system, so as to save energy and reduce operation cost on energy input.

\section{Engineering Examples}

This project is a heating - air conditioning project for a bank with a total building area of $900 \mathrm{~m} 2$. The number of layers is 2 layers, the height of the layer is $3.8 \mathrm{~m}$, and the height of the ceiling is $3.3 \mathrm{~m}$. The building is a brick concrete structure.

Cold / heat source setting: the heating heat source of this project uses solar energy and air source heat pump combined heating. The purpose is energy saving and environmental protection. The air source heat pump is used to refrigerate in summer, and the temperature of the return water is $7 \mathrm{C}$ $\sim 12$ C. (2) terminal settings: according to the nature and characteristics of the building, the air conditioning system terminal is equipped with a horizontal hidden fan coil system, which is controlled by a liquid crystal display. Users can adjust the air volume of the fan coil unit and indoor setting temperature according to the situation. (3) calculation of cold / heat load: the total cooling load required by the building is $90 \mathrm{~kW}$, and the total heat load required is $81 \mathrm{~kW}$. (4) the matching of solar energy collector area: the design of solar heating is $50 \%$ of the total indoor heat required to meet the normal heating of the system when the outdoor temperature is low. The required heating load is $40 \mathrm{~kW}$, and the operating time is $8 \mathrm{~h}$, then the total heat of the solar system is $40 \mathrm{~kW}$ $* 8 \mathrm{~h}=320 \mathrm{kwh}$. In winter, the actual heat of a solar collector per flat meter is $2.592 \mathrm{kwh}$. According to the above calculation, the required solar energy collector area is: $320 \mathrm{~kW} \mathrm{~h} / 2.592 \mathrm{kwh}=123 \mathrm{~m} 2$. According to the actual installation size of solar energy, the matching area is $117 \mathrm{~m} 2$. (5) the selection of the main engine of air source heat pump: using 1 modular air source heat pump FM -20Q (R), the refrigerating capacity of the unit is $70.78 \mathrm{KW}$, and the heat production is $75.02 \mathrm{KW}$. It can meet the requirements of use. (6) operation cost analysis: the operation mode of the system is solar energy + air source heat pump mode. The addition of solar energy saves a lot of expenses for the operation of the system. The advantage lies in reducing the startup rate and start-up time of the air source heat pump. According to the actual monitoring: the operating cost of the winter system: 17720 yuan, the operation cost per square meter in winter is about 19.69 yuan $/ \mathrm{m} 2$. Summer system operation cost: 14056 yuan, the operation cost per square meter in summer is about 15.62 yuan /m2.

\section{Conclusions}

As a kind of energy and power, solar energy has been used for more than 300 years. As one of the cleanest energy sources, in our country, the technology of heating the hot water with solar energy is relatively mature and the utilization rate is high in our country. However, because the solar energy has the disadvantages of dispersivity, instability and low efficiency, it has developed slowly in the use of heating in the residents. Combined with the characteristics of solar energy, it is necessary to choose another suitable heat source as a guarantee for the normal operation of the solar heating system. This paper analyzes the air source heat pump as a solar assisted heat source system, and considers the initial investment and operation cost in the design matching. We should maximize strengths and circumvent weaknesses, and give full play to the advantages of solar energy and air source heat pump.

\section{References}

[1] Gang H, Bing L. Intelligent optimization of solar air heating system in large scale construction of and its application[J]. International Journal of Smart Home, 2016, 10(8):99-106.

[2] Zhao D L, Li Y, Dai Y J, et al. Optimal study of a solar air heating system with pebble bed energy storage[J]. Energy Conversion \& Management, 2011, 52(6):2392-2400.

[3] Arkar C, Medved S. Optimization of latent heat storage in solar air heating system with vacuum 
tube air solar collector[J]. Solar Energy, 2015, 111:10-20.

[4] Arkar C, Šuklje T, Vidrih B, et al. Performance analysis of a solar air heating system with latent heat storage in a lightweight building[J]. Applied Thermal Engineering, 2016, 95:281-287.

[5] Michelson E, Shitzer A. Is there a need for a rock bed store? Simulation and optimization of solar air heating systems for offices with large thermal capacity walls[J]. Solar Energy, 1986, 36(2):99-114.

[6] Theunissen P H, Buchlin J M. Numerical optimization of a solar air heating system based on encapsulated P.C.M. storage[J]. Solar Energy, 1983, 31(3):271-277. 